\title{
Development of a polymerase chain reaction-restriction fragment length polymorphism method for identification of the Fusarium genus using the transcription elongation factor-1 $\alpha$ gene
}

\author{
MAJID ZARRIN $^{1,2}$, FARZANEH GANJ ${ }^{2}$ and SAMA FARAMARZI ${ }^{2}$ \\ ${ }^{1}$ Health Research Institute, Infectious and Tropical Diseases Research Center; ${ }^{2}$ Department of Medical Mycology, \\ Medical School, Ahvaz Jundishapur University of Medical Sciences, Ahvaz 61357-15794, Iran
}

Received July 14, 2016; Accepted September 28, 2016

DOI: $10.3892 /$ br. 2016.783

\begin{abstract}
Fusarium species are well-known plant pathogens and food contaminants that have also appeared as one of the most important groups of medically significant fungi. The sequences of the translation elongation factor (TEF)-1 $\alpha$ gene have been broadly employed for species detection. A total of 50 strains of Fusarium spp., including environmental, clinical and reference isolates were used for the current study. The primer sets, Fu3f and Fu3r, were used to amplify an 420-bp DNA fragment of the TEF-1 $\alpha$ gene. Double digestion with two restriction enzymes, $X h o \mathrm{I}$ and $S d u \mathrm{I}$ was used for discrimination of the Fusarium species in the TEF-1 $\alpha$ gene fragment. Double digestion of the TEF-1 $\alpha$ gene fragment from five clinically important Fusarium species were clearly differentiated from each other: The $F$. solani species complex, F. oxysporum species complex, $F$. verticillioides, $F$. proliferatum and $F$. fujikuroi. This method facilitates detection and enables verification of the Fusarium genus; therefore, it may be applied for disease control.
\end{abstract}

\section{Introduction}

Fusarium species are ubiquitous fungi extensively distributed in soil, plants and various organic substrates. This genus is an important plant pathogen, which causes different diseases and is responsible for important economic losses on crops. In humans, the Fusarium species causes a broad range of diseases, including superficial, locally invasive, or disseminated infections. Disseminated infections occur almost exclusively in severely immunocompromised patients and, currently,

Correspondence to: Dr Majid Zarrin, Department of Medical Mycology, Medical School, Ahvaz Jundishapur University of Medical Sciences, 1 Golestan Street, Ahvaz 61357-15794, Iran E-mail:mjzarrin@yahoo.co.uk

Key words: Fusarium, polymerase chain reaction, transcription elongation factor-1 $\alpha$ gene disseminated infections are the second most common mold that causes invasive fungal infections in immunosuppressed hosts, and is associated with high morbidity and mortality rates $(1,2)$. Furthermore, the Fusarium species causes allergic diseases, such as sinusitis in immunocompetent individuals and mycotoxicosis following ingestion of food that is contaminated with toxin-producing Fusarium $(3,4)$. This genus contains $>70$ species (5); a literature review of 259 cases of fusariosis between 2001 and 2005 demonstrated that 12 species were associated with infection. The $F$. solani species complex was the most common ( $50 \%$ of cases), followed by the F. oxysporum species complex (20\% of cases) and $F$. verticillioides and F. moniliforme (10\% of cases for each) (6).

Morphological identification of the Fusarium species is the primary, but most difficult, step in the detection procedure. However, for the species that cannot be reliably recognized by morphological characterization, additional analysis, such as DNA sequencing and species-specific polymerase chain reaction (PCR) assays, must be performed.

Translation elongation factor (TEF) $1-\alpha$ consistently presents as a single-copy gene in the Fusarium genus. This gene demonstrates a high level of sequence polymorphism among the closely associated species of Fusarium, even compared with the intron-rich portions of protein-coding genes, such as $\beta$-tubulin, calmodulin and histone H3. Therefore, TEF has become the choice marker as a single-locus detection tool in Fusarium $(7,8)$. The strategy that was developed in the present study consisted of novel PCR-restriction fragment length polymorphism (RFLP) analysis for detecting DNA polymorphisms in the TEF-1 $\alpha$ gene and for discrimination of the Fusarium genus.

\section{Materials and methods}

Microorganisms. Fifty strains of Fusarium spp. (including environmental, clinical and reference isolates) were used in the present study. The following reference strains were used: F. solani complex PTCC 5284, F. solani complex PTCC 5285, F. oxysporum complex IBRC-M 30067, F. oxysporum complex PTCC 5115, F. verticillioides PFCC 53-131, F. verticillioides PFCC 15-89, F. proliferatum PFCC 48-125, F. proliferatum PFCC 12-86 and F. fujikuroi PTCC 5144. The environmental 
strains were obtained from soil, and two strains used in the present study were clinical, which included $F$. solani complex PTCC 5284 and B988.

DNA extraction. Thick spore suspension $(1 \mathrm{ml})$ was inoculated in Ehrlenmeyer flasks containing yeast extract peptone dextrose medium and incubated on an incubator shaker at $200 \mathrm{rpm}$ under agitation for $72 \mathrm{~h}$ at $25^{\circ} \mathrm{C}$ for mycelia growth. The harvested mycelia were washed with $0.5 \mathrm{M}$ EDTA and sterile $\mathrm{dH}_{2} \mathrm{O}$. The mycelia were ground into a fine powder using liquid nitrogen and a mortar and pestle.

Approximately $100 \mathrm{mg}$ powdered mycelium was transferred into a $1.5-\mathrm{ml}$ tube containing $400 \mu \mathrm{l}$ lysis buffer (100 mM Tris-HCl, pH 8.0, 30 mM EDTA, pH 8.0, 5\% SDS $\mathrm{w} / \mathrm{v})$. After microtubes were boiled at $100^{\circ} \mathrm{C}$ for $20 \mathrm{~min}$, $3 \mathrm{M}$ acetate potassium $(150 \mu \mathrm{l})$ was added to each tube. The suspension was maintained at $-20^{\circ} \mathrm{C}$ for $10 \mathrm{~min}$ and centrifuged at $14,000 \mathrm{x} \mathrm{g}$ in $4^{\circ} \mathrm{C}$ for $10 \mathrm{~min}$. The supernatant was carefully transferred to a fresh 1.5-ml Eppendorf tube and $250 \mu \mathrm{l}$ phenol:chloroform:isoamyl alcohol (25:24:1, v/v) was added. The microtube was vortexed briefly and centrifuged at $4^{\circ} \mathrm{C}$ at $14,000 \mathrm{x} \mathrm{g}$ for $10 \mathrm{~min}$. After transferring the supernatant to a $1.5-\mathrm{ml}$ microtube, $250 \mu \mathrm{l}$ chloroform:isoamyl alcohol was added. The tubes were briefly vortexed and centrifuged at $4{ }^{\circ} \mathrm{C}$ at $14,000 \mathrm{x} \mathrm{g}$ for $10 \mathrm{~min}$. The supernatant was transferred to a fresh microtube, an equal volume of ice-cold 2-propanol was added, maintained at $-20^{\circ} \mathrm{C}$ for $10 \mathrm{~min}$ and centrifuged at $14,000 \mathrm{x} g$ for $10 \mathrm{~min}$. The upper aqueous phase was discarded and the pellet was washed with $70 \%$ ethanol $(300 \mu \mathrm{l})$. The ethanol was discarded and the DNA pellets were air dried and resuspended in $50 \mu \mathrm{l} \mathrm{dH_{2 }} \mathrm{O}$.

PCR amplification. The primer sets, Fu3f (5'-GGTATCGA CAAGCGAACCAT-3') and Fu3r (5'-TAGTAGCGGGGA GTCTCGAA-3') was used to amplify an 420-bp DNA fragment of the TEF-1 $\alpha$ gene (9). PCR reactions were performed with a volume of $50 \mu \mathrm{l}$, comprised of $5 \mu \mathrm{l} 10 \mathrm{X}$ reaction buffer, $2.2 \mathrm{mM} \mathrm{MgCl}, 200 \mu \mathrm{M}$ each dNTP, 2.5 units of Taq DNA polymerase (CinnaGen, Tehran, Iran), 30 ng template DNA and 50 pmol of each primer.

An initial denaturation step for $5 \mathrm{~min}$ at $94^{\circ} \mathrm{C}$ was followed by 30 cycles of denaturation at $94^{\circ} \mathrm{C}$ for $1 \mathrm{~min}$, annealing at $58^{\circ} \mathrm{C}$ for $1 \mathrm{~min}$ and extension at $68^{\circ} \mathrm{C}$ for $2 \mathrm{~min}$. The amplified PCR product ( $5 \mu \mathrm{l}$ ) was electrophoresed on $1 \%$ agarose gel in TAE buffer at $100 \mathrm{~V}$ for $1 \mathrm{~h}$ and stained with ethidium bromide. The PCR amplification of TEF-1 $\alpha$ gene resulted in an $\sim 420$-bp fragment.

RFLP analysis. Digestion with one restriction enzyme was not sufficient to discriminate the 420-bp DNA fragment of the TEF-1 $\alpha$ gene in the Fusarium species. Therefore, double digestion with two restriction enzymes, XhoI and $S d u \mathrm{I}$ (Thermo Fisher Scientific, Inc., Waltham, MA, USA) was used for discrimination. The restriction digestion reaction was performed in a total volume of $20 \mu 1$ containing 5 units of each enzyme, $2 \mu$ l Buffer O (Thermo Fisher Scientific, Inc.), $5 \mu 1$ PCR product, and Ultrapure water (CinnaGen, Karaj, Iran) to reach a volume of $20 \mu \mathrm{l}$. Digested PCR products were electrophoresed at $50 \mathrm{~V}$ for $3 \mathrm{~h}$ on $2 \%$ agarose gel in TAE buffer and stained with ethidium bromide.
Table I. Restriction fragment size (bp) of the Fusarium species TEF-1 $\alpha$ gene, double digested with two restriction enzymes, $X h o \mathrm{I}$ and $S d u \mathrm{I}$.

\begin{tabular}{lcc}
\hline $\begin{array}{l}\text { Fusarium } \\
\text { species }\end{array}$ & $\begin{array}{c}\text { TEF-1 } \alpha \text { fragment prior } \\
\text { to digestion (bp) }\end{array}$ & $\begin{array}{c}\text { XhoI and } S d u \mathrm{I} \\
(\mathrm{bp})\end{array}$ \\
\hline $\begin{array}{l}\text { F. oxysporum } \\
\text { species complex }\end{array}$ & 420 & $45,62,103,170$ \\
$\begin{array}{l}\text { F. verticillioides } \\
\text { F. proliferatum }\end{array}$ & 420 & $6,30,56,47,55,186$ \\
$\begin{array}{l}\text { F. fujikuroi } \\
\text { F. solani } \\
\text { species complex }\end{array}$ & 420 & $25,168,187$ \\
\hline
\end{tabular}

TEF, transcription elongation factor.

\section{Results}

PCR amplification of the TEF-1 $\alpha$ gene. The PCR amplification of TEF-1 $\alpha$ gene with Fu3f and Fu3r primers produced a unique band of $\sim 420$ bp for all tested Fusarium isolates (Fig. 1). The TEF-1 $\alpha$ gene fragment was sequenced for certain isolates, including the reference strains. The BLAST search in NCBI (https://blast.ncbi.nlm.nih.gov/Blast. cgi) demonstrated the TEF-1 $\alpha$ gene fragment from five clinically important Fusarium reference strains, including $F$. solani species complex, F. oxysporum species complex, $F$. verticillioides, $F$. proliferatum and $F$. fujikuroi exhibited $99 \%$ homology with the associated sequences deposited in the GenBank database.

Restriction patterns for the Fusarium strains. Double digestion of the fragment with restriction enzymes, XhoI and $S d u I$ clearly discriminated the $F$. solani species complex, F.oxysporum species complex, $F$. verticillioides, $F$. proliferatum and F. fujikuroi from each other (Table I and Fig. 2).

The restriction patterns of one clinical and six environmental Fusarium strains following double digestion using XhoI and $S d u \mathrm{I}$ are presented in Fig. 3. The digestion of the 420-bp fragment from these strains demonstrated different patterns. Strains E4, E16 and E25 were sequenced. A BLAST search showed that strains E4 and E16 exhibited 100\% homology with the F.equiseti and F. solani species complex, respectively and strain E25 exhibited $99 \%$ homology with $F$. incarnatum. Therefore, the restriction pattern strain E16 (Fig. 3) was similar to the F. solani complex PTCC 5284 (Fig. 2).

\section{Discussion}

Identification of filamentous fungi at the species level using classical techniques, such as morphological methods, is difficult and time-consuming. Novel rapid techniques are required in order to verify the Fusarium genus on time, particularly for clinical administration of patients. Rapid molecular approaches, such as PCR, DNA hybridization and DNA microarray have been developed and they may replace the classical methods. The major advantages of molecular 


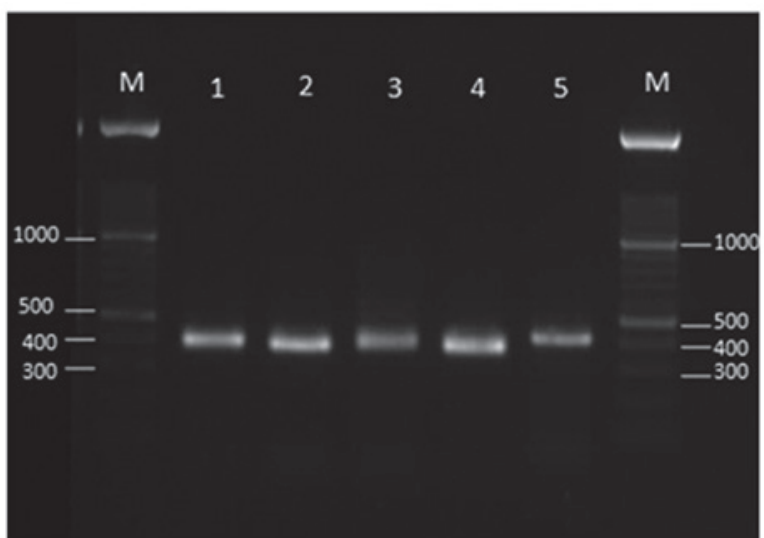

Figure 1. Agarose gel electrophoresis of transcription elongation factor-1 $\alpha$ gene products (420 bp) of the Fusarium species. Lane M, 100-bp ladder; lane 1, F. oxysporum complex IBRC-M 30067; lane 2, F. verticillioides PFCC 15-89; lane 3, F. proliferatum PFCC 48-125; lane 4, F. fujikuroi PTCC 5144; lane 5, $F$. solani complex PTCC 5284. TEF, transcription elongation factor.

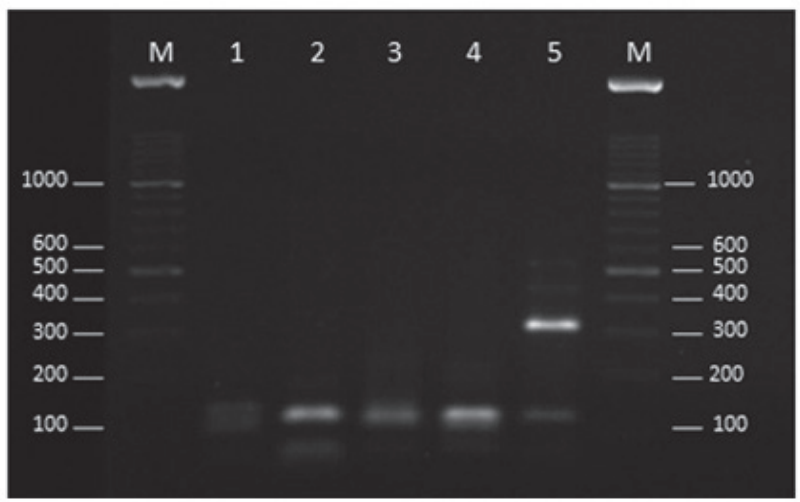

Figure 2. Agarose gel electrophoresis of transcription elongation factor-1 $\alpha$ gene products ( $420 \mathrm{bp}$ ) of the Fusarium species following double digestion with $X h o I$ and $S d u I$. Lane M, 100-bp ladder; lane 1, F. oxysporum complex IBRC-M 30067; lane 2, F. verticillioides PFCC 15-89; lane 3, F. proliferatum PFCC 48-125; lane 4, F. fujikuroi PTCC 5144; lane 5, F. solani complex PTCC 5284

approaches are their specificity and that they are completely discriminative even for closely associated species $(8,9)$.

The majority of molecular techniques are PCR-based, where the primers are typically directed to conserved regions of the ribosomal DNA gene, particularly towards the internal transcribed spacer (ITS) regions. With regard to Fusarium spp., analysis of ITS sequencing is considered unreliable for detection of strains, as they contain two paralogous, discrepant ITS sequence forms, which may cause confusion $(10,11)$. The TEF-1 $\alpha$ gene has shown optimal results for the identification of Fusarium spp. (12-14).

Guevara-Suarez et al (15) used a TEF-1 $\alpha$ gene fragment and performed a multi-locus sequence analysis of the ITS region with the RNA-dependent polymerase subunit II (Rpb2) genes, and recognized the phylogenetic species and circulating haplotypes for Fusarium isolates from onychomycosis. The pathogenic isolates to the pecan tree were identified, based on the TEF-1 $\alpha$ gene, as belonging to the F.chlamydosporum species complex, F. graminearum species complex, $F$. proliferatum, and F. oxysporum (16). A TEF-1 $\alpha$-RFLP technique was described

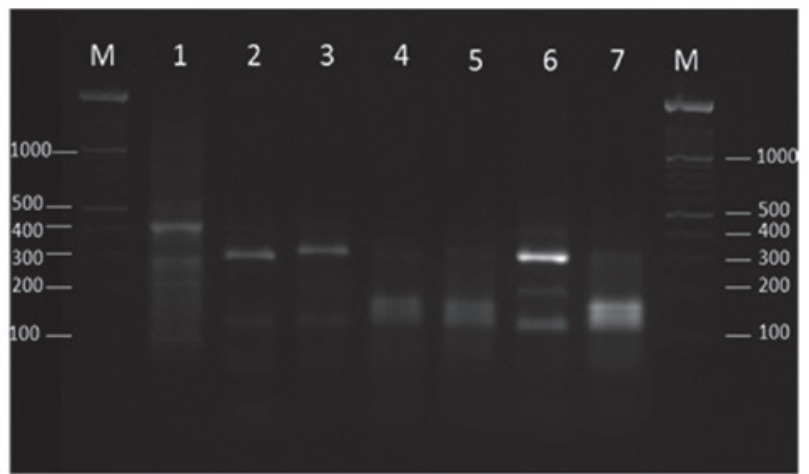

Figure 3. Agarose gel electrophoresis of transcription elongation factor-10 gene products $(420 \mathrm{bp}$ ) of the Fusarium species (lane 1, clinical isolate; lanes 2-7, environmental isolates) following double digestion with $\mathrm{XhoI}$ and SduI. Lane M, 100-bp ladder; lane 1, B988; lane 2, E4; lane 3, E16; lane 4, E17; lane 5, E18; lane 6, E20; lane 7, E25.

for the identification of the three clades of $F$. oxysporum (17). The particularly effective TEF-1 $\alpha$ gene of the Fusarium spp. encouraged the present development of a PCR-RFLP technique as an advanced, simple and reliable method for determination and discrimination of the clinically important Fusarium species.

In the current study, molecular identification was performed using the TEF-1 $\alpha$ gene and RFLP, and it was possible to discriminate between all five clinically important Fusarium species. However, further analyses are required for discrimination between other Fusarium species.

The Primer set, TEF-Fu3 resulted in an $\sim 420$-bp product for five of the Fusarium species, including $F$. solani species complex, $F$. oxysporum species complex, $F$. verticillioides, $F$. proliferatum and $F$. fujikuroi. RFLP, using double digestion with two restriction enzymes, $X h o I$ and $S d u$ I differentiated between the species. This method may facilitate detection, verify the Fusarium genus, and be applied for disease control. This PCR-RLFP method is rapid, economical and efficient for detection and discrimination of the Fusarium genus.

\section{Acknowledgements}

The present study was supported by the Health Research Institute, Infectious and Tropical Diseases Research Center, Ahvaz Jundishapur University of Medical Sciences (Ahvaz, Iran) (grant no. 92118).

\section{References}

1. Consigny S, Dhedin N, Datry A, Choquet S, Leblond V and Chosidow O: Successsful voriconazole treatment of disseminated fusarium infection in an immunocompromised patient. Clin Infect Dis 37: 311-313, 2003.

2. Nucci M and Anaissie E: Cutaneous infection by Fusarium species in healthy and immunocompromised hosts: Implications for diagnosis and management. Clin Infect Dis 35: 909-920, 2002.

3. Twarużek M, Soszczyńska E, Winiarski P, Zwierz A and Grajewski J: The occurrence of molds in patients with chronic sinusitis. Eur Arch Otorhinolaryngol 271: 1143-1148, 2014.

4. Beccari G, Caproni L, Tini F, Uhlig S and Covarelli L: Presence of fusarium species and other toxigenic fungi in malting barley and multi-mycotoxin analysis by liquid chromatography-high resolution mass spectrometry. J Agric Food Chem 64: 4390-4399, 2016. 
5. Al-Hatmi AM, Meis JF and de Hoog GS: Fusarium: Molecular Diversity and Intrinsic Drug Resistance. PLoS Pathog 12: e1005464, 2016.

6. Nucci $\mathrm{M}$ and Anaissie E: Fusarium infections in immunocompromised patients. Clin Microbiol Rev 20: 695-704, 2007.

7. Geiser DM, Jiménez-Gasco MM, Kang S, Makalowska I, Veeraraghavan N, Ward TJ, Zhang N, Kuldau GA and O'Donnell K: FUSARIUM-ID v. 1.0: A DNA sequence database for identifying Fusarium. Eur J Plant Pathol 110: 473-479, 2004.

8. Hsuan HM, Salleh B and Zakaria L: Molecular identification of Fusarium species in Gibberella fujikuroi species complex from rice, sugarcane and maize from Peninsular Malaysia. Int J Mol Sci 12: 6722-6732, 2011.

9. Arif M, Chawla S, Zaidi NW, Rayar JK, Variar M and Singh US: Development of specific primers for genus Fusarium and $F$ solani using rDNA sub-unit and transcription elongation factor (TEF-1 $\alpha$ ) gene. Afr J Biotechnol 11: 444-447, 2012.

10. Dornbusch HJ, Buzina W, Summerbell RC, Lass-Flörl C, Lackner H, Schwinger W, Sovinz P and Urban C: Fusarium verticillioides abscess of the nasal septum in an immunosuppressed child: Case report and identification of the morphologically atypical fungal strain. J Clin Microbiol 43: 1998-2001, 2005.

11. O'Donnell K and Cigelnik E: Two divergent intragenomic rDNA ITS2 types within a monophyletic lineage of the fungus Fusarium are nonorthologous. Mol Phylogenet Evol 7: 103-116, 1997.

12. Palacios SA, Susca A, Haidukowski M, Stea G, Cendoya E, Ramírez ML, Chulze SN, Farnochi MC, Moretti A and Torres AM: Genetic variability and fumonisin production by Fusarium proliferatum isolated from durum wheat grains in Argentina. Int J Food Microbiol 201: 35-41, 2015.
13. Watanabe M, Yonezawa T, Sugita-Konishi Y and Kamata Y: Utility of the phylotoxigenic relationships among trichothecene-producing Fusarium species for predicting their mycotoxin-producing potential. Food Addit Contam Part A Chem Anal Control Expo Risk Assess 30: 1370-1381, 2013.

14. Scheel CM, Hurst SF, Barreiros G, Akiti T, Nucci M and Balajee SA: Molecular analyses of Fusarium isolates recovered from a cluster of invasive mold infections in a Brazilian hospital. BMC Infect Dis 13: 49, 2013.

15. Guevara-Suarez M, Cano-Lira JF, de García MC, Sopo L, De Bedout C, Cano LE, García AM, Motta A, Amézquita A, Cárdenas M, et al: Genotyping of Fusarium isolates from onychomycoses in Colombia: Detection of two new species within the Fusarium solani species complex and in vitro antifungal susceptibility testing. Mycopathologia 181: 165-174, 2016.

16. Lazarotto M, Milanesi PM, Muniz MF, Reiniger LR, Beltrame R, Harakava R and Blume E: Morphological and molecular characterization of Fusarium spp pathogenic to pecan tree in Brazil. Genet Mol Res 13: 9390-9402, 2014.

17. Bogale M, Wingfield BD, Wingfield MJ and Steenkamp ET: Species-specific primers for Fusarium redolens and a PCR-RFLP technique to distinguish among three clades of Fusarium oxysporum. FEMS Microbiol Lett 271: 27-32, 2007. 